$P B 81-134,686$

NASA'S Aeronauricics Research and Technology Base

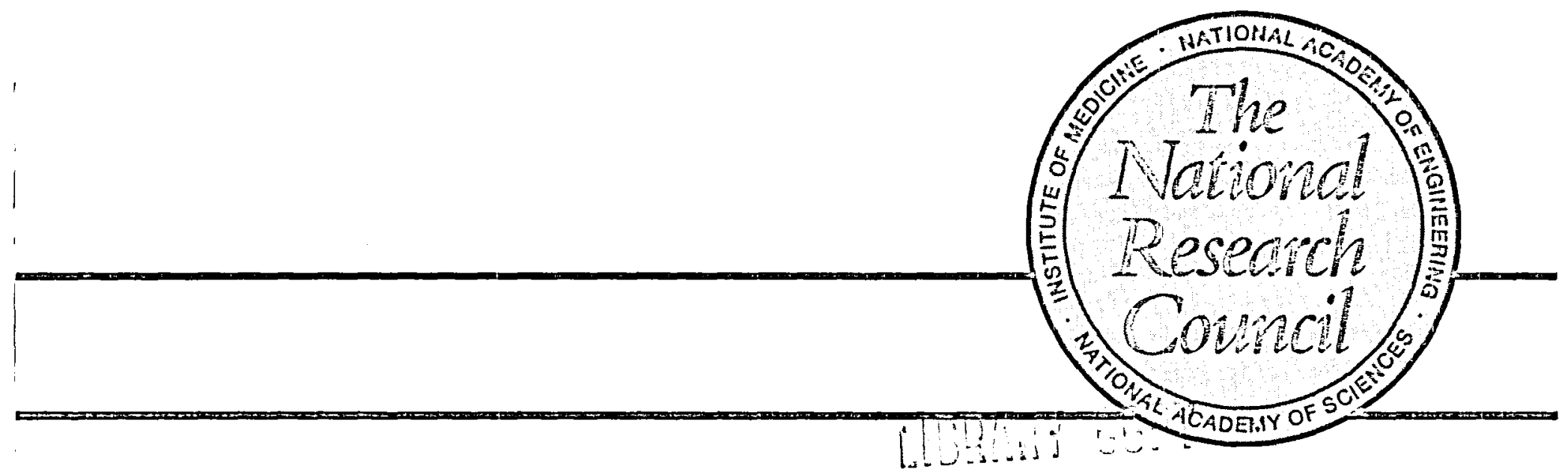

Ad Hoc Aeronautics Assessment Committee

Aeronautics and Space Engineering Board LANGLEY RESERROH CSETER

LIBRARY, PAASA

HAMHONON, VIRE:NIA

Assembly of Engineering 
i 


\section{NASA'S Aeronautics Research and Technology Base}

A Report of the

Ad Hoc Aeronautics Assessment Committee

Aeronautics and Space Engineering Board

Assembly of Engineering

National Research Council

NATIONAL ACADEMY OF SCIENCES

Washington, D.C.

1979

$N 81-22969 *$ 
NOTICE

The project that is the subject of this report was approved by the Governing Board of the National Research Council, whose members are drawn from the Councils of the National Academy of Sciences, the National Academy of Engineering, and the Institute of Medicine. The members of the committee responsible for the report were chosen for their special competences and with regard for appropriate balance.

This report has been reviewed by a group other than the authors according to procedures approved by a Report Review Committee consisting of members of the National Academy of Sciences, the National Academy of Engineering, and the Institute of Medicine.

This study and report were supported by Contract No. NASW-2342 between the National Aeronautics and Space Administration and the National Academy of Sciences.

Copies of this publication are available from:

Aeronautics and Space Engineering Board Nátional Research Council 2101 Constitution Avenue, N.W. Washington, D.C. 20418 
AERONAUTICS ASSESSMENT COMMITTEE

Robert G. Loewy, Chairman

Institute Professor

Rensselaer Polytechnic Institute

Professor Seymour M. Bogdonoff

Chairman, Dept. of Aerospace \& Mechanical Sciences

Princeton University

Richard J. Coar

Executive Vice President

Technology and Strategic Planning

Pratt \& Whitney Aircraft Group

Edgar M. Cortright

Vice President, Technical Director

Owens-Illinois, Inc.

Maxwe11 Dow

Assistant to the President

Engine Division

Cooper Airmotive

Jack L. Kerrebrock

Head, Dept. of Aeronautics and Astronautics

Massachusetts Institute of Technology

Corwin H. Meyer

Executive Vice President

Aircraft Management Associates

Robert B. Ormsby, Jr.

President

Lockheed-Georgia Company

Frederick T. Ra11, Jr.

Technical Director, Deputy for Engineering

Wright-Patterson Air Force Base

Max E. Waddoups

Design Specialist

Convair Aerospace Division

General Dynamics Corporation

H.W. Withington

Vice President, Engineering

Boeing Commercial Airplane Company

Albert J. Evans, Project Officer

Laura D'Sa, Administrative Secretary 
Arthur E. Bryson, Jr., Chairman

Paul Pigott Professor of Engineering

Chairman, Dept. of Aeronautics and Astronautics

Stanford University

Robert W. Rumme1, Vice Chairman

Vice President, Technical Development

Trans World Airlines, Inc.

Holt Ashley

Professor, Depts. of Aeronautics/Astronautics and Mechanical Engineering

Stanford University

Richard H. Battin

Associate Department Head

The Charles Stark Draper Lab., Inc.

Richard E. Black

Director, Program Engineering

Multi-National Programs

Douglas Aircraft Company

B. Paul Blasingame

Manager, Santa Barbara Operations

Delco Electronics Division

General Motors Corporation

John G. Borger

Vice President and Chief Engineer

Pan American World Airways

Richard J. Coar

Group Executive Vice President

Technology and Strategic Planning

Pratt \& Whitney Aircraft

Robert A. Fuhrman

President

Lockheed Missiles and Space Co., Inc. 
Robert R. Gilruth

Retired Director, NASA Johnson Space Center

Grant L. Hansen

Vice President and General Manager

Convair Division

General Dynamics Corporation

Ira Grant Hedrick

Senior Vice President and Presidential

Assistant for Corporate Technology

Grumman Aerospace Corporation

Robert L. Johnson

President

McDonne11 Douglas Astronautics Company

Jack L. Kerrebrock

Head, Dept. of Aeronautics and Astronautics

Massachusetts Institute of Technology

Frank W. Lehan

Aerospace Consultant

Hans W. Liepman

Director, Graduate Aeronautical Laboratories

California Institute of Technology

Robert G. Loewy

Institute Professor

Rensselaer Polytechnic Institute

Robert B. Ormsby, Jr.

President

Lockheed-Georgia Company

Maynard L. Pennell

Retired Vice President - Product Development

The Boeing Company

Harold A. Rosen

Vice President-Engineering

Hughes Aircraft Company 
George S. Schairer

Vice President, Research

The Boeing Company

William R. Sears

Aerospace Consultant

A. Richard Seebass III

Professor, Aerospace \& Mechanical Engineering

University of Arizona

Abe Silverstein

Retired Director, NASA Lewis Research Center

Sheila E. Widnall

Professor of Aeronautics \& Astronautics

Massachusetts Institute of Technology

\section{Staff :}

LaRae L. Teel, Executive Director

John Peter Taylor, Assistant Director

Albert J. Evans, Professional Associate 


\section{PREFACE}

The research and technology base activities in aeronautics of the National Aeronautics and Space Administration (NASA) consist of collecting, interpreting, and cataloging information and data as well as developing methodologies for all aspects of manned flight within the earth's atmosphere. It includes basic scientific and engineering research as well as applied research in matters of structures, materials, aerodynamics, propulsion, and avionics, which are applicable to many classes of aircraft, not just the research limited to a specific model or type. Such research forms a solid foundation for innovations in aeronautics -- as important for today and tomorrow as it has proved in the past.

This report is an evaluation of NASA's research and technology base in aeronautics. It was undertaken at the request of NASA in 1977 to assess "whether or not the program is adequate and appropriate to meet the U.S. aeronautical technology needs of the future." In the statement of task, the ad hoc committee conducting the study set out to consider the following four subjects or issues:

o U.S. aeronautical technology needs and requirements in the future.

- Objectives of NASA's aeronautics program.

- Magnitude and scope of NASA's aeronautics program.

- Aeronautics research and technology performed by NASA and others.

In this, the first report on the subject, the committee has limited itself to a survey of the adequacy of the research and technology base element of NASA's program. Additional reports will deal with the appropriateness of the balance between NASA's in-house work and its contract work with others as well as the relevance of NASA's present and proposed programs to meet the far-reaching requirements of U.S. aviation in the future.

The general goals of NASA's aeronautics program have been set forth by the agency: 
To make possible safer, more economical, and environmentally acceptable air transportation systems which are responsive to current and future national needs; to maintain the strong competitive position of the United States in the international aviation marketplace; and to support the military in maintaining the superiority of the nation's military aircraft.

In its study of NASA's research and technology base in aeronautics, the committee visited the agency's four research centers to review the ongoing and planned work in each. The committee was at the Lewis facility at Cleveland, Ohio, on March 16-17, 1977; Langley at Hampton, Virginia, April 14-15, 1977; Dryden at Edwards Air Force Base in California, May 17-18, 1977. The meetings at each were characterized by oral presentations by NASA staff, followed by informal discussion. These produced a large amount of useful background, data, and insights for the committee's use.

For its assessment, the committee considered, in addition to the elements customarily included in NASA's own program of research and technology (RGT) base activities, additional research that the committee identified as having a basic nature. This included work currently conducted in NASA's systems technology program and its experimental programs.

This report should not be regarded as either detailed or comprehensive. It is in the nature of assessments like this that deficiencies are often highlighted, while aspects of the program that are soundly conceived, appropriately structured and supported, and superbly managed are mentioned briefly if at all. The committee trusts that the extent to which its report seems negative in tone will be ascribed to this characteristic of critical assessments. After taking stock of NASA's R\&T base, the committee neither lacks confidence in nor is it dissatisfied with NASA's overall conduct of the base element of its aeronautical research and technology program. To the contrary, it finds the program merits strong support.

After a short introduction to the topic, the report summarizes some general problems detected in NASA's aeronautics research program and then provides more specific commentary in sections on each of the four research centers. 
CONTENTS

INTRODUCTION

GENERAL PROBLEM AREAS 4

FUNDING

WORKFORCE 4

BALANCING PROJECTS AND RESEARCH 5

FUNDAMENTAL RESEARCH

$\begin{array}{ll}\text { LEAD CENTER CONCEPT } & 7\end{array}$

PROBLEM AREAS IN CENTER PROGRAMS

$\begin{array}{ll}\text { LEWIS RESEARCH CENTER } & 8\end{array}$

$\begin{array}{ll}\text { LANGLEY RESEARCH CENTER } & 17\end{array}$

DRYDEN FLIGHT RESEARCH CENTER 21

AMES RESEARCH CENTER 23

EMPHASIS AND OPPORTUNITIES IN CENTER PROGRAMS 29

LEWIS RESEARCH CENTER 29

LANGLEY RESEARCH CENTER $\quad 32$

DRYDEN FLIGHT RESEARCH CENTER 36

AMES RESEARCH CENTER 38 



\section{INTRODUCTION}

The pace of progress in aviation gained momentum with the outbreak of World War I. Both Britain and Germany rapidly developed new reconnaissance and fighter airplanes. In each country a great deal of research in such matters as air turbulence and aircraft design was performed at special centers -- the Royal Aircraft Factory at Farmborough, England, and the Aeronautical Research Institute at Gottingen, Germany. Nothing like those centers existed in the United States until 1915 when, largely at the urging of Charles Doolittle Walcott, Secretary of the Smithsonian Institution, and Alexander Graham Bell, a member of the Smithsonian board of regents, the Congress attached a rider to a Navy appropriations bill to create the National Advisory Committee for Aeronautics (NACA).

The new committee, consisting of 12 volunteer members, was to "supervise and direct the scientific study of the problems of flight, with a view to their practical solution." Moreover, it was directed. to conduct and coordinate laboratory research in aeronautics as the principal way of advancing civil and military aircraft in the U.S. In due course, NACA pioneered the development and operation of research and development facilities for general use, the collection and dissemination of basic research information, and the exploration and testing of new designs and developments. Its work in science and technology has contributed to advancing the aerodynamic design of aircraft, airplane engines, and structural innovations for designing, fabricating, and testing many kinds of aircraft.

As a result of World War II, the United States aircraft manufacturing industry became preeminent, the Air Force was established as a separate military arm, and the NACA was greatly strengthened to pursue new and far-reaching advances in aeronautics. The first Soviet sputniks changed that emphasis. In 1958, the Congress established an extensive space program under the National Aeronautics and Space Administration (NASA), with NACA as its nucleus. Though NACA had been abolished as a separate federal agency, its facilities were integral to the newly formed NASA. Thus, NASA took over NACA's aeronautical research establishment at Langley Field at Hampton, Virginia, the Ames Research Center at Moffett Field, California, the Lewis aircraft engine laboratory at Cleveland, Ohio, 
and the Flight Research Center* at Edwards Air Force Base, California, as well as some 8,000 employees.

Besides its responsibility for aeronautical research in support of civil and military aviation, NASA, under the National Aeronautics and Space Act of 1958 (P.L. 85-568) was given the overall responsibility, among other things, for developing the systems to conduct the exploration and exploitation of space, as well as the planning and management of manned and unmanned space missions.

After 1961, when a manned landing on the moon became a national goal to be achieved by the end of the decade, the space mission understandably absorbed NASA's primary attention and most of its energy and resources. As a consequence, the aeronautics portion of NASA's responsibilities languished.

In the mid-1960's, however, the Congress and the White House Bureau of the Budget showed increasing concern with improving the state of aeronautical research in the federal government. Even so, NASA's commitment to an enlarged aeronautics program had diminished. Since its inception, the agency had undergone significant changes. Its successes with the Mercury, Gemini, and Apollo manned flights and its investigations of space, which provided an important new understanding of the planet Earth as well as the solar system, had earned great renown for the agency as uniquely capable of conceiving and managing large and complex projects.

A distinctive feature of NASA's philosophy of management today is the application of a cost-benefit analysis whenever this technique is considered appropriate to justify specific projects or activities. The "systems" viewpoint essential to such an analysis has led those responsible for aeronautics at NASA to conceptualize aeronautics research of a basic character in terms of broad "packages." Examples of such packages are STOL (Short Takeoff and Landing) aircraft technology, supersonic transport technology, and aircraft engine efficiency.

The organization of research and technology base activities into such packages has broad public appeal as well as intrinsic merit in providing a management tool for dealing with the overall aeronautics program. This practice continues and, in recent years, some of these technology packages have evolved into product-oriented projects involving equipment development with some similarities to new commercial or. military aircraft and component developments. As such, they require a commitment of large sums of money for completion, and they are conducted on schedules that militate against the exploration of unexpected but promising paths for further investigation. For these reasons and others, such "package" projects have been considered by some in the aeronautics community as a threat to basic research and technology programs, which however otherwise meritorious, do not fit within one of the accepted packages.

*Subsequently named the Dryden Flight Research Center after Hugh L. Dryden, Director of NACA from 1947 until 1958, when he became Deputy Administrator of NASA, a post he held until his death in 1965. 
In the $1970^{\prime} \mathrm{s}$, the U.S. aviation community became concerned that NASA's approach to RGT activities was characterized by increasing rigidity. According to the conventional consensus, something had gone wrong with aeronautical innovation and, consequently, some serious questions were raised about the momentum of aviation advances. Indeed, NASA itself became concerned that its programs may not be fulfilling U.S. aviation needs. It was at this point that the agency asked the National Research Council to assess the adequacy of NASA's research and technology base program on which future problems in aeronautics will be solved and technical innovation will be supported. An ad hoc committee of the Research Council's Aeronautics and Space Engineering Board was organized to determine the facts on which it could reach a judgment about NASA's research and technology base program for aeronautics. The material covered in this activity, taken together, forms the foundation for innovation in aeronautics-as essential today and tomorrow as it proved in the past, during the 43 years of the NACA--and as such it is important to national security, international trade competitiveness, and domestic economic growth. 
GENERAL PROBLEM AREAS

\section{Funding}

The committee finds that many of the deficiencies in NASA's aeronautics program are associated with the funding level assigned to individual activities. While this report recommends program reductions as well as redistributions of effort in several areas, the committee has observed instances in which the budget is insufficient to achieve NASA's stated objectives. Funding is, of course, a political decision, and the committee was neither asked to review NASA's budget nor does it consider such an evaluation within its scope of expertness. However, the committee is obliged to note instances in which productive research, currently underway at NASA, is inhibited by funding limitations and where important new opportunities in areas of high potential cannot be undertaken at all because funding is unavailable.

\section{Workforce}

NASA personnel strength has been declining steadily over a number of years. For the most part, the reductions have occurred within the agency's space programs, while the man-years devoted to aeronautics have held constant. The committee is concerned, however, that further reductions in NASA's total workforce will almost certainly result in lower staff levels in the aeronautics programs, posing a threat to the R\&T base activities in aeronautics.

Even the maintenance of a constant level of man-years devoted to R\&T base activities poses certain dangers. The committee points out that important opportunities have developed in recent years in avionics, materials, structures, and the man-vehicle interface. Although it is difficult to quantify any specific "deficit" in the research workforce in relation to these opportunities, the committee is concerned that NASA may be neglecting some promising avenues and that, therefore, the agency may be falling short of its stated goals in aeronautics. 
A more subtle danger associated with the lack of growth in aeronautics research is that it prevents the entry of younger personnel with fresh ideas and enthusiasm. Also, the number of technicians and clerical staff often are reduced in order to maintain the professional staff. Inefficiences result when engineers and scientists are then required to perform non-professional chores. The committee urges that NASA explore all possible means for reducing the negative effects of its personnel ceilings. Furthermore, it recommends that NASA seek ways to nurture generic research by providing a "success ladder" for the nonmanagerial researcher -- i.e., for productive research that is free of management responsibilities. The committee is aware that, if successful, such an effort could provide a beneficial example for a wide segment of government and industry.

Balancing Projects and Research

The definition of "projects," as expressed here, relates to the discussion in the Introduction in which the concerns in the aeronautics community regarding the detrimental impact of project "packages" on basic research was described. Over the past several years, NASA has been successful in winning support for aeronautics projects aimed at recognized national needs and, as a result, has been increasing the total resources available for its programs. The committee recognizes the benefits to be derived from projects. Precisely because the project approach is successful, however, projects can cause problems in a research organization that is responsible for long-range research and technology. The committee considers that a carefully balanced mixture of projects and research is important for a meaningful NASA program in aeronautics.

Among the reasons for avoiding an imbalance in favor of projects:

- Projects have design-point orientation, with specific objectives for the relatively near term; they usually do not generate results of wide applicability.

- Project management appears to be the best way to succeed within NASA. Potentially productive research people become involved in the selling and management of projects and, in many cases, in the details of organization and bureaucracy. Their new ideas for research and technology can of ten be submerged in a management function.

- Projects have to be defined with specific goals and with specific timetables. The success or failure of a project is easy to evaluate in a reasonably short time. Therefore, the project staff is not likely to gamble. Instead, it tends to avoid taking large risks for high payoffs, so that there is a strong tendency to settle for small advances in the state of the art with relatively low risk. 
- Once committed, projects require timely completion. In periods of budgetary constraints, there is a tendency to curtail research in order to make sure that overruns and unforeseen problems are covered by allocated funds within the project.

Projects contribute in important ways to the R\&T base:

- Projects place heavy emphasis on all contributory disciplines being brought together, causing useful interactions among the research people.

- Projects are practical demonstrations. New equipment must function wel1, performance is measured against the previous experience, and success needs to be achieved.

- Projects often provide the ultimate reality. New equipment must function, new performance is measured against the old and it is less likely that a successful conclusion will be achieved if a critical area has been neglected.

- Projects provide milestones indicating how far the state of the art in the various contributory disciplines has advanced and delineating the factors that may have lagged and become limiting.

NASA must -- and the committee is convinced that NASA does -carefully weigh and monitor these aspects in formulating its overall program in aeronautics. The pressures on behalf of projects are great, however, and the potential consequences of imbalance are farreaching. Therefore, as a worthwhile principle, the committee recommends that the R\&T base be supported strictly on its own merits and that each project be undertaken on its own merits.

$\underline{\text { Fundamental Research }}$

The committee concludes that the RET base program in many cases can be improved by increasing the pursuit of fundamentals. What is now described as research is often no more than device-testing. In some cases, emphasis is placed on a trial-and-error approach that amounts to the "cut-and-try" of new hardware, rather than on the underlying physical basis for phenomena. The committee considers more systematic analysis of concepts prior to testing to be highly desirable.

The lack of such analysis contributes to program formulations that are deficient on two counts: (1) the reason for pursuing a given research effort is frequently not described in terms of results expected, should the sought-after advance be achieved, but the work often is undertaken simply because a new concept appears to be feasible and generally promising, and (2) even when the results are clearly worth the effort, the program often is simply a test of a point-design embodiment of the idea, without sufficient investigation 
of the phenomena to provide insight as to the optimum solutions or the sensitivity of the results to variations in the pertinent variables.

\section{Lead Center Concept}

Recently NASA has assigned specific roles and missions to its four aeronautics centers. Langley is the lead center for conventional take-off and landing (CTOL) aircraft, high-speed aerodynamics and structures research; Ames is principally responsible for low-speed flight, including helicopters and V/STOL aircraft; Lewis specializes in propulsion, and Dryden in experimental flight-testing. The committee finds that the lead center concept is an effective management tool for creating centers of technical excellence, for the

efficient use of unique facilities, and for overall program efficiency. 
PROBLEM AREAS IN CENTER PROGRAMS

Lewis Research Center

Many promising developments in propulsion technology are either too uncertain or their maturity too distant, say 15 to 20 years off, for industry to undertake supporting them. The application of such advances in a new engine usually requires a longer lead time than for corresponding airframe advances. A matter of concern to the committee is the possibility that commonality is diminishing between military and civil aircraft engines, a point made in the Report of the U.S. Air Force Scientific Advisory Board's ad hoc committee on Gas Turbine Technology issued in January 1976. In the past, a large share of the burden for research and development on gas generator components has been borne by military programs, mainly in the Air Force. The resultant gas generators have been applicable to advanced civil aircraft engines as well as to high performance military engines. The diminishing commonality, coupled with the requirement for increased emphasis on noise reduction and fuel conservation, suggests that NASA must assume the responsibility for component RGT for advanced, durable civil engines that operate with reduced noise and fuel consumption. At the same time, NASA's development of engine test capability should take cognizance and advantage, as much as possible, of the testing capabilities that already exist in the Department of Defense laboratories, notably the Arnold Engineering Development Center, Tullahoma, Tenn., and the Naval Air Propulsion Test Center, Trenton, N.J., as well as in private industry.

These are general comments that apply to the Lewis Research Center, which was established in World War II to advance the state of aircraft engine technology.

Computational Fluid Dynamics

The committee finds the Lewis Center to be predominantly hardware oriented. Its research is to a large extent experimental, with only a relatively small fraction devoted to theoretical work. In many areas more theoretical analyses and fundamental experiments are needed. As a start to remedying this deficiency, the committee recommends that Lewis undertake the development and application of computational fluid dynamics to internal flows 
for use in engine research. Limitations in the current state of the art are recognized, but the work at Ames Research Center in computational fluid dynamics has shown what can be done and a start should be made now at Lewis.

\section{Increased Use of Industry Support Services}

The Full-Scale Engine Research program is an example of the hardware orientation at Lewis. In terms of workforce, it is one of the center's largest programs. The stated objective of the program to study and understand the dynamic interaction between engine components is sound. But the program, as described to the committee, involves the calibration of existing engines and diagnostic work that duplicates the results obtained by others, and the personnel and resources devoted to Ful1-Scale Engine Testing seem out of proportion to the benefits received. Recognizing the appropriateness of full-scale engine testing for evaluating interactions among such advanced components as control modes, augmentors, and nozzles, the committee recommends that NASA investigate the feasibility of letting service contracts to industry to provide technicians for the routine operation and maintenance of test engines so as to allow the more highly qualified NASA personnel to concentrate on research on advanced components.

\section{University Relationships}

Grants to university research groups provide an excellent means for obtaining and utilizing capability and expertise not otherwise available to NASA. Management of the university component requires care, however. On the whole, the Lewis relationship with the university community is productive, but in some areas the available funding has been distributed too thinly among too large a number of universities. Where this occurs, it is difficult to achieve a viable program or a useful working relationship. Barring an increase in funds for support of the university effort, the committee recommends that Lewis consider a reduction in the total number of its university grants and contracts so that a "critical mass" of support can be provided for those universities that possess the expertise and capability to contribute to the understanding of the most important (high priority) items.

\section{High Pressure, High Temperature Turbine Research}

The turbine, with the compressor and fan, is at the heart of any advanced engine, and to a large extent these components determine engine performance and operational suitability (energy, noise, and pollution). A few years ago Lewis embarked on the development of its new High Pressure, High Temperature Turbine Facility, which represents a major change in approach to turbine testing. There is a difference of opinion in the engine RED community regarding the best 
way to test turbines. Some hold that turbine testing is best done in gas generators, after the pattern of the Air Force's Advanced Turbine Engine Gas Generator (ATEGG) program. The Lewis approach is to conduct tests of the isolated turbine in the new turbine facility. Both approaches have merit, and the committee takes no side in the matter. However, if the Lewis approach is to be productive, a sustained commitment will be required to place the facility on line. Such a commitment is not evident to the committee. The turbine facility has lagged several years behind its intended startup date, partly, it would seem, because of funding and personnel limitations. The committee recommends a substantial and sustained effort to bring the new turbine facility "on line" and put it into full use as soon as possible because of its importance to Lewis' turbine research. The committee also finds that the turbine research group would benefit from the addition of more young, highly qualified personnel to attack the fundamentals of the fluid and solid mechanics of turbines.

\section{Research on Pollution, Fuels and Combustors}

Engine exhaust pollution of the atmosphere is a problem for which fundamental data are lacking. Such data are needed to reduce emissions of oxides of nitrogen, because no practical system has been devised as yet that meets the standards established by the Environmental Protection Agency for gas turbine engines.

This area provides another example of a program in which the approach has largely been cut-and-try. Some worthwhile reduction in gas turbine contributions to air pollution has been achieved during landing and takeoff, but an organized examination of fundamental parameters is essential for further progress. Specifically, the influence of combustor-inlet wakes and turbulence, tuel composition and preparation, pressure loss, combustor wall configuration and cooling, and internal kinetics, including turbulence, needs to be examined.

A pollution program redirected to mount an attack on the fundamentals should also include instrumentation development to measure species in situ. Moreover, instrumentation and measurement techniques should be developed for the investigation of emissions variability and data interpretation procedures should be devised for improved regulatory enforcement.

The research on pollutant reduction is proceeding at crosspurposes with fuels and combustors research. The objectives of the fuels and combustor work is to improve economy and efficiency. It does not, however, take into account their use in an operating environment of strict anti-pollution requirements.

Fuels research is a relatively new program initiated at Lewis in fiscal year 1974. The objective of the program "to evaluate the potential characteristics of future jet aircraft fuels and determine effects on engine components" is good. Baseline data are needed to catalog the effect of fuel characteristics on engine operation so that changes in fuel specification do not occur that may degrade flight safety or have serious economic consequences. Care should be taken, 
however, to avoid sidetracking the effort into fuel synthesis, except to the extent absolutely necessary to provide test fuel. The program should concentrate on the evaluation of different fuel characteristics.

With regard to the research on combustors and augmentors, the stated objective of the work to improve durability is a good one that responds to a real problem. Here again, however, the approach relies heavily on hardware cut-and-try, so that the committee recommends more more emphasis on understanding the combustion process. Experiments to determine fundamental behavior, efforts to catalogue known combustion behavior, and the development of analyses leading to a reliable, appropriate mathematical model are necessary to provide a scientific basis for combustor design. Unlike other engine components, combustors do not easily scale, either dimensionally or for pressure or temperature. The Lewis facility affords an opportunity to examine the influence of independent variables at full-scale conditions.

More emphasis is also needed on the structural behavior of combustion hardware, on combustion improvement at low pressures and temperatures (particularly augmentors), on combustion stability at rich mixtures (rumble), and on reducing combustion noise.

Finally, the committee strongly recommends that the three currently separate programs -- pollutant reduction, combustion, and fuel research -- be integrated into a single program.

\section{Engine Structures}

The committee finds that the Lewis effort in structures is substantially behind the current state of the art. The performance, reliability, and safety of modern gas turbine engines require careful integration of the structural and aerodynamic aspects. Research into the dynamics of engine structures is an urgent need, but important areas, such as turbine engine rotor dynamics, receive no effort at all in the Lewis program. Lewis has considered, and the committee recommends, establishing a meaningful program in engine structures. Such an effort would benefit from a closer relationship with Langley. In particular, structures experts have to be responsive to the needs of aerodynamicists and prepared to work with them to eliminate the mechanical impediments to high performance. In addition, the committee recommends that the structures program be separated from the materials program, a move that has been considered by Lewis. When structures activity is subordinated to a materials organization, and both are separated from component technology, unrealistic component approaches can result. Invariably, the solutions to problems center on new or modified materials, and little effort is put into the development and application of analytical tools or efforts to design innovative structures. Further, the materials effort itself loses the beneficial effects of an independent structural review. 
Engine-Airframe Integration

An important area in propulsion research now being neglected is engine/airframe integration. This is a critical design problem. Many of its aspects have not yielded to efforts to provide a satisfactory performance prediction methodology. NASA's R\&T program should oversee, integrate, and coordinate propulsion aspects from the free stream far ahead of the aircraft to far behind it.

The present engine-airframe integration program has many separate and individual pieces, some of which are mentioned later in this report, but insufficient attention is paid to the complete engine system. Judgments as to critical problem areas or those with the highest potential for payoff may often be seriously incomplete in the absence of the results of analysis of whole systems, yet no NASA center appears to have this responsibility. The committee recommends that a center be given the lead-center responsibility in the area of engine/airframe integration and the charge to establish a program of research in the area. The committee takes no position as to whether Lewis or Langley would be the more appropriate lead-center.

\section{$\underline{\text { Fans and Compressors }}$}

The fan and compressor, as key components of advanced engines, should receive high research priority. The Lewis approach in its fan and compressor work has been to support basic research in universities, to design and test in-house, advanced high-speed stages, and to contract with industry for the design and testing of a series of stages covering a wide range of tip speeds. This is a well conceived and well balanced program that has produced good results. However, the initiatives that can be undertaken in-house are severely limited by the lack of personnel. For example, the Lewis group acquired a major new responsibility for aeroelastic work about two years ago and only one new man to deal with it. The work would benefit greatly from the addition of several qualified people. As in the case of the research effort on turbines, the effort on fans and compressors lacks enough young, highly qualified personnel attacking the fluid mechanics and solid mechanics of these components in a fundamental way. The present personnel are heavily loaded with contract supervision. Lewis, therefore, does not presently provide the leadership that its position and its total resources should engender.

\section{Inlets and Nozzles}

The program described to the committee on inlets and nozzles is merely proposed. Little is currently being done in this field. It appears that NASA is downplaying its effort and responsibility in the area of inlet research. The Ames Center is no longer performing inlet work. The committee judges the effort proposed by Lewis on 
analytical design methodology for inlets to be worthwhile because it promises to produce results of general applicability. The committee recommends pursuing the fundamentals of inlet distortion and boundary layer control and the auxiliary inlet work directed to reducing transonic spillage drag. The high angle of attack and sideslip inlet performance effort is questionable and should be given low priority in light of a recent comprehensive study made by General Dynamics for the Air Force's Flight Dynamics Laboratory.*

In the area of nozzle drag, Lewis is deferring to Langley, and the Lewis effort on nozzles in general has been steadily decreasing since fiscal year 1974. This is a critical area that needs fundamental research attention. The committee commends the nozzle/ air frame integration research underway at Langley, which is discussed later in the Langley Center section.

Propulsion Noise

Engine noise will continue to be a central problem for commercial aviation. In terms of regulation, the critical question is: What level of noise suppression is socially acceptable, economically feasible, and technically attainable? Considering the long lead time involved, the aircraft and engine manufacturers necessarily must adopt a conservative design stance on these questions. To offset this tendency, the committee considers it essential that NASA adopt a technically aggressive position, one based on a forward looking research program.

The principal question at Lewis is the balance between basic research and technology and hardware demonstration programs. As stated before, much of NASA Lewis research in recent years has been largely hardware testing, not theory and analysis. The propulsion noise program could be improved by increasing the emphasis on theoretical work, combined with fundamental experiments on advanced components. The cry "We don't understand the fundamentals of engine noise," often heard in the late 1960's, still resounds.

While Langley has the main responsibility within NASA for noise reduction research, Lewis has the obligation to perform research on engine noise. In general, the schedule and pace of the research work are adequate. An exception of some importance exists in the studies of forward velocity effects. There are major gaps of understanding here, preventing ground programs from being devised that would be useful in investigating airplane noise problems. Fundamental work, both theoretical and experimental, is needed and should be at the heart of any effort in this area. Also, better understanding of the differences between static noise levels and those experienced in forward flight would enable the application of static noise tests in engine development.

\footnotetext{
Advanced Inlet-Airframe Integration Concepts, AFFDL-TR-77-47, July 1977
} 
V/STOL Propulsion Research

In recent years, the Lewis program in V/STOL propulsion has been steadily decreasing. The phasing down reflects, in part, what the center perceives as a "lack of obvious need." Funding devoted to this area has dropped to one-tenth and personnel to one-half from fiscal year 1972 to fiscal year 1977. The committee was informed that the Navy's interest in V/STOL (small carriers, "sea control ships") is not seen as sufficiently defined to be taken into account in Lewis' program plans.

Nonetheless, after about two decades of research with few service applications, there are signs of useful advances in non-rotary wing V/STOL technology, and much of the current Lewis effort is well worthwhile. Lewis' high angle of attack V/STOL inlet development and variable pitch fan programs are among those worth doing, as is its work on mechanical drive systems and engine controls. Moreover, the two-dimensional nozzle developments offer clear potential for V/STOL applications and entail problems that need to be solved before applications will be feasible or, alternatively, before it can be established that the problems are so difficult to solve that the benefits of 2-D (two-dimensional) nozzles are not likely to be realized in practical applications. There is overlap here, with applications of interconnected ducts as proposed for gas-driven multiple-fan V/STOL arrangements. This work, too, is worthwhile.

Although associated with Ames' mission, there is a need for technology developments aimed at self-contained V/STOL nacelle packages in which exhaust air from the aft fans is used to provide vertical force through over-or under-the-wing blowing and the nose fan exhausts through a cascade that can direct flow down or aft, for lifting or cruising, respectively. Further, in this design approach, both aft and forward downward flows must be modulated at sufficiently high frequencies to provide VTOL control as well as lift. Some of the problems likely to be encountered in attempting to develop such configurations include the effect of flow non-uniformities on the fans as a result of downstream obstructions. These are the kinds of problems on which Lewis expertise can be brought to bear effectively.

\section{Advanced Engine Concepts}

Many of the Lewis research programs on advanced engine concepts are aimed at V/STOL applications, and the earlier comments under V/STOL Propulsion Research apply here as well. Among the more promising ideas not mentioned earlier is the application of $j$ et flaps on stator blades for cooling and for providing the equivalent of variable pitch.

The difficulties encountered in predicting some of the problems associated with advanced engine concepts, particularly for V/STOL aircraft in which upstream and downstream flow non-uniformities are involved, argue for much greater use of analytical techniques. Among these, Lewis should devote a substantial effort to the application 
of the kind of computational fluid dynamics work being carried on at Ames. In the case of the Lewis Research Center, of course, concentration would be on internal aerodynamics, with attempts to account for variable duct cross-sections, asymmetrical obstructions, downstream cascades, and boundary layer effects.

At the same time, increased aeroelastic and structural dynamics analysis capabilities for fans, stators, and turbine blades should be pursued, with the ultimate objective of combining static flow capabilities with time-varying aeroelastic calculations, to arrive at a truly dynamic aerodynamic and structural analysis capability. for future advanced engines. At present, the committee finds almost no effort directed to that goal.

\section{Instrumentation}

Instrumentation research at Lewis is relatively new, a group having been established in August 1974. Lewis is to be commended for initiating much needed research in instrumentation. It is timely to assess the effort at this stage to assure its growth in the proper direction.

Presently, the scope of the effort is narrow. All of the programs are directed to testing feasibility or to demonstrating technology. There appears to be little either in the way of basic research or work with a direct connection to high priority needs. Emphasis should be placed on instrumentation to obtain the kind of data needed for engine monitoring or control, i.e. on sensors that can withstand the hostile environment of the engine.

Individuals knowledgeable about the key problems are needed to work on advanced instrumentation. For example, composite materials are used in modern engines, and knowledge of the mechanisms that cause composites to fail is needed to develop means to detect failures or potential failures.

\section{Propeller Research}

The direction of NASA turboprop research seems to be almost completely concerned with making propellers competitive with fan jets for high subsonic speeds at high altitudes and on long-range flights, where fan jets work best. Here the efficiency edge of the turboprop is minimized. Airline travel is predicted to grow, yet the opinion prevails that there will not be specialized aircraft for the fairly short-haul flights of 300 to 500 miles or less. The margin of the turboprop's advantage over turbofans is greatest for aircraft that operate with the smallest percentage of engine-on time spent at cruise altitude and cruise speeds, but where much fuel is burned in the aggregate of takeoff, climb-out, approach, and landing on multiple-leg flights. It is to these short-haul operations that NASA turboprop technology programs should be directed. Here the efficiency of propellers is not in dispute, and the focus of the program should be in noise reduction (internal 
and external to the aircraft), the reliability of gear boxes and variable pitch control systems, structural integrity, and long blade life. Lewis should be working toward propeller gear-boxes and controls with maintenance characteristics comparable to those of fan jet engines. Such a program would be a true technology program, with applications for both general aviation and advanced short-haul commercial aircraft. The committee was not made aware of these elements in NASA's current turboprop program. 


\section{$\underline{\text { Langley Research Center }}$}

As the original NACA laboratory, established in 1920, the Langley Center is developing the broadest range of fundamental technologies underlying aeronautics. The committee finds the Langley research and technology program in aeronautics well focused and its level of technical competence good. Langley's capability for and attitude toward in-house research is strong, and its record of research accomplishments and contributions to U.S. military and civil aviation is one that inspires confidence that U.S. leadership in aviation will continue.

\section{Materials and Structures}

The payoff in aircraft performance to be derived from the use of composite materials in aircraft structures is well documented, and the primary benefit of weight reduction has been demonstrated. NASA's program is commendably oriented toward converting this potential to commercial hardware. The components flight service program is excellent -- well planned, conducted, and documented.

The committee concludes, however, that NASA could make additiona1 and perhaps even more significant contributions by applying its talents to the basics. For instance, U.S. domestic fiber processes are not competitive with Japan's, and the first decade of military applications has exposed some problems concerning environmental durability and detail design. The quality of the environmental work described to the committee and the moisture/diffusion research leaves something to be desired. The molecular engineering work on polimides is good applied research, and because the composites market is relatively small, this work is not likely to be initiated by the large polymer firms. Langley can be criticized, however, for focusing on only one resin, which happens to be in the same polymer family being investigated at the Lewis Research Center.

Fail-safe design technology needs to be developed and demonstrated. On the question of manufacturing research, however, the committee recommends that NASA should remain on the periphery of such studies because private industry is better equipped for such work. 
NASA's aircraft structures effort is centered at Langley, and most of the research is devoted to structures made of composite materials. The committee considers this emphasis to be well placed, but the programs should be strengthened and directed to advancing basic understanding of structural mechanics, failure mechanisms, and proportioning concepts. For example, the current compression panel work is very good. Computer codes developed at Langley have been used to configure a set of test panels that showed there are both serious gaps in what is known about the failure mechanics of composites and serious deficiencies in the ability to predict such failure. These results, together with design optimization data, should form the basis for continuing intensive work on the fundamentals of composite compression panel design and failure mechanics. Such structural analysis efforts will have greatest value if they are closely tied to experiments, and any temptation to make analysis or design codes a tool for industrial design should be resisted until the fundamentals are better understood.

Similar technology development to arrive at new structural concepts for advanced metals should al so be included in the NASA structures and materials program. Such work should include structural materials appropriate for airplane components operating at high temperature and should address corrosion, fracture mechanics, and joining problems with these advanced metals.

The aeroelasticity research at Langley is also of good quality. Active controls research, unsteady aerodynamics, and structural dynamics have been combined, and with the use of the 16-foot Transonic Dynamics Tunnel the effort promises to aid substantially in the development of technology to actively suppress flutter for clean aerodynamic surfaces.

In view of its concerns, the committee recommends that materials and structures R\&T base activities be reviewed, concentrating on developing a focused program of depth in selected areas and recognizing that some areas of lower priority may have to be eliminated. The committee considers that basic fiber and matrix systems and highly innovative design approaches represent the most advantageous areas and that such a program should have the objective of setting the pace of second generation systems.

\section{Avionics}

Avionics is becoming one of the most pervasive of aeronautical technologies. It is an innovative field in which the U.S. probably leads the world. It should continue to be emphasized for the benefits to be obtained for many aspects of aircraft performance, handling qualities, and overall operations. The avionics program is conducted to some degree at all four research centers: Langley has prime responsibility for basic research and advanced component technology, Ames for component integration and advanced system concepts, Lewis for advanced propulsion control systems, and Dryden for flight test of advanced concepts and systems. 
Langley chracterizes the elements of its program by describing (i) navigation, communications, and all weather systems as "the aircraft's. link with the outside world," (ii) aircraft propulsion and control functions as "intra-airframe aspects," and (iii) the pilot's cockpit controls and displays as "the interface between airframe and pilot."

NASA's fly-by-wire work on helicopters is excellent, as is the aeroelastic mode stabilization work mentioned earlier and the whole effort in terminal-configured vehicles aimed at improving traffic capacity at busy airports and at conserving fuel. Such programs should receive great emphasis by NASA, especially the efforts to achieve reliability in the associated avionics and controls.

Even though avionics holds great promise of major advances for all classes of aircraft, it is not being fully explored and exploited. Areas of application with great potential benefit to aviation include (i) integrating propulsion, aerodynamics, and aircraft altitude controls to improve performance and conserve fuel, (ii) compensating for smaller tail lengths and sizes and negative stability margins for reduced airframe size and weight (iii) stabilizing aeroelastic modes and minimizing response to gusts for reduced structural weight, and (iv) automating take-off, climb out, approach and landing, cruise control, and air traffic control to conserve fuel, improve safety, and control noise.

Because of the immense potential offered by avionics research and technology, the committee recommends that NASA initiate the actions necessary to define and establish a bolder program. While there is great need for close collaboration between NASA, other government agencies, and the aviation industry, some of the elements identified here probably will never receive sufficient attention by any group or agency other than NASA. The substantial work being conducted by private industry on its own and under contract to the Department of Defense is largely directed to providing equipment and solutions to meet immediate requirements or for military applications. NASA's work that is directed to today's hardware and software is of questionable value -- e.g. there is some question whether Langley's program in low-cost avionics for general aviation is reasonable in view of the electronics industry's massive capabilities and its clear market incentive to develop such equipment on its own. The committee, therefore, recommends that NASA look to the future in avionics and that the agency's avionics effort be increased to make it a major component of NASA's aeronautical R\&T base activity. In this connection, Langley appears to be the NASA center with the greatest competence, enthusiasm, and activity in this area.

\section{Aircraft Noise Effects}

Langley's aircraft noise research centers on the effects of noise on the vehicle and in the human reactions to noise -- including passengers, crew, and the general public on the ground. It also deals with changes in vehicle design and operating procedures to alleviate 
noise. All aspects are in need of further study, because solutions for noise may create problems in other areas.

The committee considers that reducing the impact of noise on the general public is more urgent today than making advances in the alleviation of cabin noise. Improved understanding of subjective human reactions to noise and to different levels of noise is needed to attain better "normalizing" and to provide direction to developments aimed at more acceptable noise signatures.

Turbo Jet/Fan Engine Nozzles

Langley's research in nozzles, concerned primarily with nozzle/ airframe integration, is a sound program. The magnitude of the drag associated with the engine nozzle and aircraft aft-end, together with the uncertainty associated with thick boundary layers and jet interactions, makes such matters well worth pursuing.

Recent emphasis on analytical, as well as experimental, results is a step forward and should receive increased emphasis. Langley should concentrate on the aft-end and nozzle drag with the resources available. The addition of the comprehensive experimental program to optimize nacelle installations on transport aircraft is appropriate, but it should be accompanied by a parallel analytical effort. 
Dryden Flight Research Center

The prime responsibility of the Dryden Center in the R\&T base is the conduct of flight research and the development of flight test methodology. In this respect, Dryden differs from the other three NASA research centers in that it conducts a more specialized kind of R\&T base activity. Accordingly, the committee elected not to assess Dryden's individual programs in detail and in its review emphasized 'the definition of Dryden's most appropriate role in NASA's aeronautics RET base program.

While the prime mission of Dryden is flight testing, the committee became aware that the center is also seeking to build a capability for basic research. It can be argued that this is necessary if the Dryden staff is to be sufficlently knowledgeable to do flight research properly. However, Dryden should not attempt to acquire in-depth expertise in disciplinary research that duplicates what is being done well at other centers. The committee is concerned that the practice of assembling pockets of disciplinary expertise may be detrimental to the conduct of Dryden's primary mission of flight test research.

One example of Dryden's propensity to engage in disciplinary research (and there are probably others) is its five-member aeroelasticity group, responsible for performing structures and aeroelastic analyses in conjunction with flight results. The committee considers this to be disadvantageous for several reasons. With no disparagement intended, the analytic work conducted by the small group at Dryden cannot equal the quality of that conducted by the much larger group performing similar studies at Langley. Indeed, the practice tends to insulate the Langley analysts from the real world of flight and hampers the critically important effort to correlate predictions with flight test data. Moreover, it tends to dilute Dryden's capability to carry out its primary responsibility for flight research.

The committee recommends that NASA consider, as an alternative to the development of an in-house disciplinary research capability at Dryden, providing incentives for young personnel who have gained experience in disciplinary research groups at the other centers to serve as "technology managers" on two-year or three-year tours of duty at Dryden. At Dryden they would be responsible for mobilizing 
the proper disciplinary support by the other centers for its flight research. In this way, most or all of the predictive and correlative calculations in aeroelasticity, noise reduction, stress analysis, and other disciplines would be performed by an appropriate group at another center to the advantage of Dryden. Such an arrangement also would provide an important means for providing opportunities as well as incentives for upward-bound personnel destined for future NASA management jobs.

\section{Automated Data Reduction}

A second major concern of the committee was the lack of a first-rate automated data reduction system, which is a prerequisite if Dryden is to realize its potential as the leader in flight testing. Updating of the computer data system at Dryden should be a first order of priority to permit greater accuracy and higher data rates. Greater information handling productivity is possible with the central computer capability and talented staff at Dryden. Also, simplification of the process used to prepare for active tests is possible by standardizing instrumentation and processing software.

Benefits that ought to have accrued from the existing central computer have not yet been realized. Accordingly, the committee recommends that NASA re-examine its present information handling system with a view toward improving its effectiveness and productivity. Because there is sufficient central processor capability at Dryden, it should be cost-effective to install the pre-processing equipment and software that would allow the center to reap the benefits of previous computer investments. 


\author{
Ames Research Center
}

The Ames Center leads the aeronautics research in the technologies of low-speed flight, including helicopters and V/STOL aircraft as well as of flight simulation and life sciences. Rather than spread its resources thinly over many disciplines, Ames has chosen to concentrate on a few areas in-depth. The committee regards this as a prudent strategy, for it has enabled Ames to clearly establish its leadership in several of the most potent aeronautical technologies.

\title{
Computational Fluid Dynamics
}

The Ames effort in computational fluid dynamics in recent years has been a success story. The general approach being taken by Ames is notable: theoretical methods for predicting aerodynamic flows are being adapted to computers, and the results compared with experimental data gathered from ground test facilities at various scales and from flight tests. One question regards the balance struck between solving problems because of the potential usefulness of the results and solving problems for such other reasons as the likelihood of success or because a particular problem has caused difficulty in the past, independent of whether its solution has any real significance for advanced aircraft design.

The committee considers the discipline to be fairly mature and the professionals involved in its development ready to take the next step, namely 3-dimensional inviscid flows and 2-dimensional viscous flows. However, it is also timely and important to apply the methodology to some real problems. Some useful applications are not being pushed to the extent they should. For example, although computational fluid dynamics is an Ames specialty and internal flow characteristics is mostly a Lewis problem, computational fluid dynamics should be helping to solve engine problems, as noted in the assessment of the Lewis programs. Similarly, examples of computational fluid dynamics seen by the committee did not include 2-dimensional studies of blown-flaps as proposed for V/STOL aircraft. The committee considers this a natural extension of considerable value to the research on V/STOL configurations. It is recommended, however, that the relatively small group working to advance the computational 
methodology should continue and a separate group be established to undertake and assist others in the concerted effort needed to apply the new methodology to design problems.

\section{Large Scale Computer}

As seen by Ames, the next phase in the computational fluid dynamics program will require a rather specialized memory-intensive computer with computational capabilities at least 40 times greater than the Star or IIliac IV and 100 times greater than the CDC -7600 . Such a computer would be a national facility, managed and operated in much the same way as a major wind tunnel. The committee suggests proceeding with some caution, however. Computational capabilities have in some ways already outdistanced present knowledge about the appropriateness of aerodynamic flow models. Turbulence is one example: part of the current work in computational fluid dynamics is to determine when certain time-averaged quantities may be used and if their use is dependent on the configuration under study. In view of such uncertainties, it would seem only prudent to keep the next generation computer intended for computational fluid dynamics sufficiently flexible to accommodate substantial changes in computational models without major loss in computational efficiency. In other words, if a computer is to be specially designed for computational fluid dynamics, it must not be so highly specialized that it effectively rules out the use of some variation, possibly ones that have not yet been considered, in the mathematical model. Widely different views exist about what type of computer facility will best advance fluid mechanics calculations. Roughly, the types can be categorized as

- supercomputers in parallel (the Ames approach)

o cheap replacements for current computers

o one microcomputer per grid point

The committee notes that there is probably as much computing speed in fluid dynamics to be gained by algorithm development as by computer development. Moreover, the algorithm development required for efficient use of future machine arrays may differ substantially from that used with present computers. In view of the uncertainty, Ames should proceed cautiously in developing any new, large-scale computational facility, which may well become obsolete before it can be placed in use.

Low-Speed Vehicle Aerodynamics

This is an important area of effort and it covers a broad spectrum. The potential for improved safety of all vehicle classes and for providing the technology for new uses of aircraft is high and a substantial fraction of Ames' resources is being devoted to the 
low-speed aerodynamics program.

The approach in this area has generally been to perform paper studies to determine whether a specific aerodynamic concept is worth pursuing. However, the paper studies have often been shallow, with the upshot that some unworthy projects were undertaken while others with great potential were neglected. Two cases in point: the heavy-lift airship idea, which involves several major problems whose importance would be exposed by proper analysis, and the effort directed to turboprop aircraft configurations, which does not seem to be pointed toward the solution of such critical problems as propeller noise, control, and the aerodynamic interference between the propeller and airframe.

V/STOL (Vertical and Short Take-off and Landing), R/STOL (Restricted and Short Take-off and Landing) and helicopter work all seem reasonable, with the high point being the joint NASA/Army tiltrotor research aircraft program. With regard to some of the basic work, such as higher harmonic cyclic control on helicopter rotors to minimize blade loads, control loads, and fuselage vibration, the committee recommends that Langley's capability in aeroelasticity to analyze such configurations be continued at a brisk pace. The committee understands that Ames is now responsible for complete systems. While it is reasonable to view a rotor with its controls as a "system" and, therefore, under Ames' responsibility, it would be a mistake for the center to attempt to duplicate some of the disciplines that are now so capably studied at Langley.

The committee considers it only a matter of time before large "flying cranes" and 100- to 200-passenger helicopter transports will be operating in world markets. There are major technological problems relating to large helicopters that have not been addressed. These concern rotor speeds (and, therefore, fundamental blade natural frequencies) that are low for large rotary wing aircraft and fall within the frequency range of human pilot control-input. In addition, natural frequencies for large fuselage structures tend to be in a lower range than ever before. The resulting response to pilot input needs to be investigated. There will, undoubtedly, be handling problems similar to those encountered when small fixed-wing aircraft were scaled up to large fixed-wing aircraft. Rotor acoustics are likely to cause a different sort of problem for very large, slow-turning rotors. For these reasons, NASA could profitably utilize the Army's partially completed and presently mothballed Heavy Lift Helicopter in a program of research and experimental testing. Such a program might receive some support by the Army and Navy, and seems well justified on the basis of providing technology for future world markets.

\section{Flight Safety and the Human-Vehicle Interface}

The areas of safety and the man-vehicle interface are closely related and extremely important. All of the research centers are engaged in safety studies in one way or another without significant duplication. Ames appears to be the most involved at present and 
coordinates well with other centers and other agencies.

The committee recommends that the resources devoted to aircraft safety research be increased because of its importance and closely coupled interrelationship with almost every other technology. The limit on the rate at which increasing resources can be efficiently used, however, will be a function of the ability to find people who are interested in and can contribute to the subject and the establishment of a mechanism for setting priorities among the various existing problems.

A notable case in which NASA has responded to proven needs for safety research is the wind shear study. The search for ways to effectively deal with wind shear effects, in time to avoid accidents, is commendable. The wake turbulence programs also are worthwhile in dealing with potentially dangerous effects. The number of accidents resulting from these efforts are not yet large. NASA's efforts in minimizing the effects of the wake vortex are important with regard to the question of future limitations to airport capacity. The approach to the problem, however, has been too cut-and-try, with not enough effort in either fundamental experiments or theoretical analyses to enhance the basic understanding of vortex phenomena. Present plans attempt to correct this imbalance, but these do not go far enough. More basic research is needed.

The human contribution to the safety problem clearly is of major importance. Where it manifests itself at the man-vehicle interface it is the least tangible, communicable, and understood portion of the total aeronautical system. Yet, with about 80 percent of all accidents in flight attributed to human error, the research has the greatest potential for improved aviation safety. Current efforts are divided between Langley and Ames. Such Langley work as the crew/ system interaction studies, for example, appears to be more relevant to reducing accidents than any of the other contributory technologies such as flight controls and auto pilots.

To emphasize this point further: an aspect of flight safety and the man-vehicle interface that has been largely neglected and needs emphasis is the decision cycle from the standpoint of the pilot's physiological, psychological, mental, and workload status. How to determine what makes a pilot good or bad is crucial to aircraft safety.

Almost all accidents are the result of emergencies requiring sudden decision making events or situations that preoccupy or overload the pilot for a period of time great enough to cause the accident. To improve aircraft cockpits, more knowledge is needed about human limitations, yet basic human limitations have never been carefully or scientifically defined. For instance, the effect of combinations of fatigue, cabin altitude, and time on human performance has not been quantified; nor has the effect of fatigue on capabilities in emergency situations, although most accidents are known to happen at the end of the flight. To improve the safety record, and prior to re-designing the man-machine system, research needs to be conducted to determine more clearly when and how the individual exceeds his limits. 
The complicated and interrelated nature of this subject suggests that one center be designated responsible for integrating the whole. Yet, concentrating the actual work at one center does not seem necessary; it breaks down into separate components requiring relatively straightforward applications of technology to achieve significant progress. Coordination among the many agencies with interest and involvement in this matter is urgently needed. Furthermore, the role for NASA as expert, coordinator, and mediator seems evident.

Ames appears to the committee to be the logical choice to become the lead center for studies of safety and the human-vehicle interface, with specific responsibility for coordinating with all other pertinent organizations. The center's responsibilities should include setting up separate plans for safety research that apply to the military, airlines, general aviation, and agricultural aviation. (The types of accidents vary so widely from group to group in these four categories that specific applications in one group will not necessarily benefit the other). Such plans should provide for determining the operational areas in which the worst accidents or the greatest number of accidents occur, in order to ascertain patterns of repeatability and cause as we11 as to set research priorities.

Efforts being made elsewhere in this field should, of course, be determined so that NASA can concentrate its efforts on the areas that can result in the best return on investment in terms of reducing human fatalities from aircraft accidents. It is anticipated that an important part of this research will turn out to be a determination of the characteristics of situations that demand performance beyond human capabilities.

\section{Avionics and Flight Controls}

In its discussion of the Langley program, the committee has made specific recommendations concerning avionics and expressed some reservations regarding the value of the work being conducted at Ames in this area. In general, NASA's attempt to act as a focal point for industry and the Federal Aviation Administration (FAA) as a way of identifying needs and interests through workshops, symposia, and working sessions appears well conceived and should be pursued. However, there appears to be a tendency to intrude into the traditional FAA/applicant certification process, which the committee considers to be highly undesirable and should be continually monitored and discouraged.

A deficiency in the program appears to be centered around today's hardware/software technology, and in this field of rapid growth, the emphasis placed on this research may not be appropriate five years hence. Certain simulation results would be useful, such as establishing the pilot's role in redundancy management for extended operational environments (STOL aircraft, control-configured vehicles, automatic landing systems) and developing non-piloted simulation methods for evaluating a system's statistical parameters which employ digital 
processors i.e., faster than real-time simulation techniques. The studies involving software certification and control are clearly necessary and should be pursued. 
In this section, the committee notes a number of center activities which, while soundly conceived and executed, would benefit by an expansion of the work or, in some cases, relatively minor shifts in emphasis.

\section{Lewis Research Center}

High Temperature Engine Materials

This program consists of research to define superior materials for the components of aircraft turbine engines that must operate in a high-temperature environment, the most notable being the turbine blades. The scope of the effort provides multiple and physically distinct options covering metal alloys, including powder metallurgy and ceramic materials.

This program is an excellent illustration of the benefits of a cooperative effort that has been developed between NASA, industry, and universities. The materials and concepts developed in the program are being used by the industry. In this respect, the program at Lewis is well conceived and well performed. However, no work appears to be going on to resolve the problem of failure mechanisms for high temperature engine materials. Also, the serviceability of flawed materials is a problem that requires study. Another problem that concerns the committee is critical metals that are available only from foreign sources, such as cobalt and chromium. The committee recommends that a research effort should be undertaken to attempt to find substitutes for imported metals.

\section{Propulsion Controls}

This program concerns the understanding of the dynamic behavior of propulsion systems and the application of control theory so that maximum performance can be maintained safely and reliably even if sudden and unexpected disturbances are encountered. The work includes the development of the methodology to empirically predict airframe/inlet/engine interactions, and the technology, including 
fiber optics, for practical and reliable digital control systems. The results of the program could have major impact on both military and civilian applications. The two major programs in the immediate future -- application of the multivariable control concept and the development of digital control components -- represent important steps in establishing digital electronic propulsion control systems. Also, the program to predict aircraft/inlet/engine interactions may provide insights into other interactions, such as the problem of dual-spoolcycle interactions.

The overall program outlined for the next five years is well thought out and coordinated. The program elements are blended to develop the technology in a reasonable time period. It operates on a realistic schedule with respect to the level of technology involved. In short, the program is a balanced approach to providing the control technology that will be required in the 1980's. In addition, the program includes cooperative endeavors using the special talents of several government agencies in conjunction with various contractors. Such cooperative programs provide a highly effective means of technology transfer to users and can be cost-effective.

However, the committee recommends that the scope of this activity be expanded in two areas: First, the multivariable control concept that integrates propulsion system and aircraft controls should be verified in flight. This kind of technology is difficult to evaluate in a wind tunnel. A program may be appropriate in conjunction with some of the present efforts by the Air Force Flight Dynamics Laboratory. The schedule and level of effort would depend greatly on the availability of appropriate test vehicles in the 1980-1982 period. Second, electronic control reliability should be verified in flight. It will be necessary to establish the capability of industry to produce digital electronics with the reliability required in the environment in which they will operate in propulsion control systems. Tests in the actual operational environment could be performed by installing electronic controls in various applications and turning them on without the capability of controlling any mechanism. By monitoring their operation, knowledge would be gathered to improve reliability estimates and to detect those areas requiring improvements. By involving different contractors to build the controls, the required industrial base for manufacturing capability would be developed.

Propulsion for General Aviation

This is a new program in which Lewis is studying a number of engine cycles as they might apply to general aviation aircraft to improve fuel consumption and reduce emissions that pollute the atmosphere. Diesel engines, rotary engines, and stirling engines are being studied to select the most promising of these for comparison with improved conventional engines.

General aviation is an area of aviation in need of continued research that is receiving increasing attention by NASA. General aviation is a $\$ 500$ million a year industry which embraces 5,000 
businesses, employs 250,000 people, and builds 14,000 aircraft a year. The present general aviation fleet consists of more than 168,000 aircraft. There are 13,000 airports in the U.S., and airlines serve fewer than 500 of them. Each year some 100 million people travel on general aviation aircraft, mostly air taxis, commuter transports, and business jets. This class of aircraft also includes agricultural aircraft, which service 180 million acres of cropland per year and take part in forest fire patrol and police surveillance and law enforcement. Obviously, general aviation has a sizeable effect on the life and economy of the United States.

The General Aviation Turbine Engine (GATE) work at Lewis is good. The committee commends the Lewis effort on small (200/100-pound thrust) turbine engines. Agricultural aircraft and helicopters can use such engines.

The committee recommends that work be initiated on the effects of 100-octane, low-lead fuel in the operation of general aviation engines. The use of such fuel in engines designed for $80 / 87$ octane fuel now causes engine troubles in general aviation aircraft. New airplanes can be equipped with engines using 100-octane fuel, but there will be a significant number of airplanes flying for many years with the older engines.

The committee also recommends that the Lewis propeller program (now exclusively occupied with high subsonic speed propellers) be broadened to include general aviation propeller technology, which has received little attention and essentially no advancement in the past 30 years. For example, over half of the agricultural airplanes flying are equipped with propellers developed in the middle to late 1930 's for airplanes cruising at $200 \mathrm{mph}$ at altitude. These same propellers are now being used at $100 \mathrm{mph}$ at sea level.

\section{Power Transfer}

The program in power transfer deals with a broad range of research that includes lubrication theory, gears, shafting, bearings and seals, and advanced power transmission. The state of the art in this area needs to be advanced and the available knowledge put into the public domain. Many opportunities exist for useful work in this area on such problems as engine-case seals, overrunning clutches for helicopter transmissions, variable nozzle actuation mechanisms and large, heavy-lift helicopter gear boxes. The Army program substantially augments the Lewis program and additional support is provided under NASA's Aircraft Energy Efficiency (ACEE) program. However, with the cancellation of the Army Heavy Lift Helicopter Program, there is no meaningful research effort on helicopter transmission systems for large helicopters. The Army's program showed that large planetary gear systems have substantially different problems from smaller sized systems. Accordingly, much needs to be done before the large systems can be made both light and reliable. Lewis has an opportunity to make a worthwhile contribution to power transfer technology by pursuing research on large aircraft gear box designs. 


\section{Fluid and Flight Dynamics}

Langley's program includes the development and application of computational fluid dynamics to the aerodynamics of advanced aircraft, the study of turbulent flow boundary layers to reduce skin friction and aerodynamic noise, stall/spin prevention, and the use of gases at cryogenic temperatures for developing flows for aerodynamic research at high Reynolds numbers. The work under this program typifies what the committee considers to be appropriate RET base work. Langley is concentrating its effort in fluid and flight dynamics research to key areas that ought to lead to progress, and the present activities and plans appear to be reasonably balanced.

The area of Computational Fluid Dynamics is well staffed and the program well executed. A broad range of problems, whose solutions will have many practical applications, are being examined, and significant progress is being made. However, the work should be closely correlated with experimental programs to advance understanding in areas where computational techniques and mathematical modeling are not yet adequate. If this work does not already include crossflow or bodies with upswept afterbodies at high angles of attack, it should be expanded to do so. Vortex flow control techniques for 3-dimensional bodies should also be investigated and should have as an objective the prediction of the power input required for vortex control. This recommendation applies to lifting surfaces as well.

The work in turbulent flows is excellent. The results of this outstanding endeavor should assist industry e.g. a "breakthrough" reduction in skin friction drag coefficient might be achieved.

The flight dynamics program meets the perceived critical requirements. The results of work in this area are urgently needed by the aircraft industry. Therefore, the close ties with industry and the Langley group's responsiveness to industry's needs are likely to result in useful work.

The committee was pleased to see the area of experimental methods and test techniques treated as a distinct effort. It is obviously a key in continued experimental activities and deserves specific attention. The main emphasis of the program is tied to 
the National Transonic Facility, as it should be, although a considerable amount of this research will be applicable in many other test facilities. The work on wall interference is particularly important in the transonic area, but the present activity is primarily concerned with flow fields and should be integrated with the work on noise and the wall boundary layer effects which are so large at transonic speeds. Here is where the application of results from work on the Quiet Mach 5 Tunnel must be applied if the National Transonic Facility is to have the best possible flow. The idea of using a slotted wall as a nozzle wall has been proposed by Klebonoff (one of Langley's consultants) and has been examined by the Air Force's Arnold Engineering Development Center. This approach should be included in Langley's efforts.

High Speed Aerodynamics

The work grouped in this area is directed to the aerodynamics of transport aircraft, hypersonic aircraft, fighter aircraft maneuverability, and missile aerodynamics.

The significance of transport aircraft to the nation's economy makes this area one of high priority. The balance between fundamental and applied research is considered satisfactory, and the research leaders are highly qualified. The schedule and pace of the effort, however, appear to be too slow. In cases where flight test results exist, as in the F-8 Supercritical Wing and the TACT (Transonic Aircraft Technology) programs, the documentation of results and the comparison with wind tunnel data have been less than satisfactory. Relating the data to theory would make all of the test results more useful. In addition, increased emphasis should be placed on "off design" characteristics of configurations, as these are usually the design conditions for which loads and stability and control are critical. One specific area of high interest to aircraft designers is high Reynolds number data on advanced airfoils, which would provide the data that are needed for decisions regarding the use of such airfoils in new aircraft designs.

Langley has the only group in the country with any major activity and competence in hypersonic aircraft aerodynamics. The program is a reasonably planned effort of long standing. The program has concentrated on airbreathing vehicles for the hypersonic flight regime, which has led to an interdisciplinary approach. The effort at Langley is focused on propulsion, with very little being done on total aerodynamic characteristics, such as stability and control and aerodynamic performance. The aerodynamic and propulsive interactions found in subsonic and supersonic flight are intensified in hypersonic airbreathing vehicles, and both technical areas need to be worked together as well as independently.

When viewed from the perspective of providing technological options, the present program is worthwhile; if the work is successful, an application may be forthcoming. For example, the technology could be applied to cruise missiles and one-stage-to-orbit 
space vehicles. Such uses should be exploited. Emphasis should be placed on the missile application since this is likely to develop first.

In the area of fighter aircraft maneuverability, the balance among structural weight, engine size, and maximum aerodynamic $1 \mathrm{ift}$ and aerodynamic efficiency have significant impact on the effectiveness of a fighter aircraft. In addition, the importance of aircraft stealth presents a technical challenge. Achieving a configuration with outstanding aerodynamic characteristics and, at the same time, a low observable signature on radar or infrared detectors significantly increases the difficulty of the aerodynamic and propulsion design problems.

Langley's emphasis on vortex flows is highly appropriate, and the correlation of the analytical effort with the experimental is commended.

The work on fluid injection to improve aerodynamic performance is interesting, but needs to be continually weighed against the associated penalties (presumably propulsive). The committee's finding is not meant to be negative, but rather to encourage a degree of realism. The maneuvering capabilities of missiles is a subject that needs increased emphasis. A missile's margin of performance over the aircraft it is attacking can best be increased by providing increased maneuverability without relinquishing speed capability. The combination of NASA work in support of the military, together with its independent aerodynamic design effort in this area, is viewed as extremely useful and serves both parties well. However, the committee recommends an entirely new approach to missile design that will use the full capability of the aerodynamicist in fundamental design approaches. To realize the maximum benefit, an understanding of the aerodynamic interactions between the various components is required.

\section{Aircraft Operations and Safety}

Langley's efforts on hazards avoidance and elimination and aircraft ground performance are good programs that appear to be adequately supported. Even so, the Terminal Configured Vehicle program is an important program and increased support is recommended. It is also recommended that two other high priority research opportunities cited by Langley be undertaken -- namely, lightning and clear-air turbulence detection.

In the area of the crew/system interface, the Langley program emphasizes efficiency of operation at the expense of safety. This should be rectified. The tools developed to record the visual reactions of crew members are very effective, and NASA should now encourage industry and the FAA to apply them in defining and developing efficient cockpit layouts.

\section{Airbreathing Engines}

This effort is directed to the hypersonic flight regime, and much of the earlier comment on the hypersonic program under 
High-Speed Aerodynamics applies here. The committee considers this program to be outstanding, and suggests that its scope be broadened to use 3-dimensional computational techniques to define interactions and improve integration of the engine and airframe, particularly at the after-body and nozzle junctures.

\section{Low Speed Aerodynamics}

Langley's stall/spin research is excellent and the airfoil research well done. The scope of the work should be widened and the committee suggests that the five opportunities cited by Langley -- aerial applications, general aviation aircraft propellers, handling qualities/controls/displays for instrument flight, helicopter noise reduction, and rotor elasticity -- are all appropriate for such increased effort.

\section{Propulsion Environment}

The study directed to understanding the flow structure of a jet is a most impressive and important piece of work. No one else has studied the basic phenomena of noise through the jet efflux. All studies have been limited to the effects of the jet without considering the cause. The committee considers this to be a necessary program, and recommends much increased interaction with industry. 
Dryden F1ight Research Center

\section{Research Vehicles}

Flight testing is a critical part of NASA's aeronautical research. The nation needs a facility like the Dxyden Center to conduct flight tests on appropriate research aircraft. Traditionally, when specific major objectives have been established that require the construction of a new research vehicle, NASA, usually in conjunction with the military services, has initiated major design and development efforts, resulting in specific experimental aircraft to explore new frontiers of flight. Examples of such research aircraft are the X-15 of the $1960^{\prime}$ 's and today's Tilt Rotor Research Aircraft.

The development and construction of such experimental aircraft, although costly, are essential whenever flight test results cannot be obtained in any other way. The committee is aware that such programs must be carefully reviewed and fully justified, and because of the cost this approach will not be utilized frequently. However, many new military aircraft incorporate technical advances in performance, payload capability, and subsystems that the Dryden Center could put to use. Adding research instrumentation to test aircraft would contribute significantly to the technological data base. In addition, minor modifications to the aircraft can be made which provide further opportunities for improving the understanding of advances in the state of the art. Frequently, full scale development aircraft, complete with instrumentation, have been transferred to Dryden for this purpose. The mutual benefits of cooperation in flight test research for NASA and the military services achieved in the past justifies its pursuit in the future. An increase of emphasis on cooperation with the Navy needs to be attained and effort made, during the manufacture of the development aircraft, to have the specific instrumentation required for Dryden's program built in.

Dryden's mission should be expanded to include commercial and general aviation aircraft. For this purpose, the practice of obtaining such vehicles by direct purchase or lease is probably the best approach.

\section{Remotely Piloted Research Vehicles (RPRV)}

The Dryden Center has pioneered the capability to conduct flight tests with unmanned, remotely controlled vehicles. Dryden's unique 
environment, together with the staff's background and experience with sophisticated aircraft, offers the potential to conduct tests that are beyond the limits of wind tunnels and are either too costly or too high risk for manned test flight. Programs already being conducted, such as the investigation of stability and control in stall and post-stall flight, demonstrate the bright prospect of the RPRV concept. 


\section{Low Speed Vehicle Aerodynamics}

The Ames program on R/STOL and VTOL pursued under the Low Speed Vehicle Aerodynamics program is following a constructive plan, which appears to have a suitable mixture of analysis and experiment. Some of the work also can be useful for conventional take off and landing aircraft. The problem of engine simulation, however, should be examined in depth. Because the existing means of simulating engines require a large mass rate of secondary air and because the temperatures of the exhaust are not simulated, the adequacy of simulation needs to be quantified. This is especially true for configurations in which the exhaust strikes and scrubs external surfaces. It is not apparent how far Ames is planning to go in developing and calibrating engine simulators, but this work should have high priority. The results of such work are likely to have applications outside the VTOL field.

The Air Force's Advanced Medium STOL Transport (AMST) prototype program affords a cost-effective way to acquire full-scale flight data to augment the model data base across the complete spectrum of flight conditions and technology specialties. The AMST prototypes represent the most advanced aircraft totally designed for short takeoff and landing operation.

Initial flight data acquired during the AMST prototype test phase revealed the need for understanding the environment to which the structure is subjected with upper surface blowing. This work has been highly successful, providing an excellent technology data base, with spinoff benefits for the Air Force's development program. Future efforts will broaden the technical areas of interest. The committee recommends, however, that NASA bring industry into the planning of the experiments at a sufficiently early date to be effective. This is deemed essential if the needs of the aircraft industry are to be given full consideration.

In the area of turbulent flows, the work of the Ames Center is fundamental and appears to be progressing fairly well. The programs are of key importance, and the research group is competent, knowledgeable, and, although clearly computationally oriented, fully 
aware of the experimental needs of the program. There is still a long way to go in this area, but the committee perceives the effort as significant.

The program in unsteady aerodynamics is centered primarily around the 11-foot tunnel, with a well-distributed theoretical program to compute unsteady transonic flows carried out both in-house and elsewhere among an excellent group of contractors. The experimental program seems well defined. Its emphasis is on airfoil sections for advanced rotor designs, and future plans to study dynamic stall and 3-dimensional effects are both realistic and important.

The program on experimental methods is a responsible effort in basic support of all test facilities. The organization of a separate section concentrating on experimental methods shows the center's awareness of the necessity of supporting the wind tunnel programs through such a group. The group is involved in research into testing methods, as well as in the development of such non-intrusive instrumentation as infrared detection of flow separation and the development of the laser velocimeter and holography. Both of these systems are on the verge of providing valuable data.

The committee's discussion of the work on advanced transonic wind tunnel test sections left some questions whether this research was being coordinated, whether the best possible solution will ever be determined from the individual approaches, and whether the best inputs to NASA as a whole are being obtained from the outside community. NASA has a number of advanced transonic test sections under study at both Langley and Ames. It is clear that Langley's work with Klebanoff and rod walls and the Ames concept of an improved slotbaffle geometry should be coordinated.

The extrapolation of wind tunnel results to higher Reynolds numbers is a persistent problem. Understandably, it is again part of the program being carried out at Langley. The correlation between work at Ames and Langley is not clear and, therefore, needs to be examined.

The approach in the Airfoil and Wing Aerodynamics program is excellent. There is a proper mix of theory and experiment. Future plans to obtain validation test data in both wind tunnel and flight are highly endorsed. The CAPAIR (Comprehensive Aerodynamic Prediction for Aircraft) program shows promise for providing a new and valuable research and development capability.

The effort in High Angle-of-Attack Aerodynamics is considered useful, but the objective should be broadened to include transport aircraft. Evaluation of the high angle-of-attack characteristics during the design phase should lead to more efficient aircraft, regardless of the maneuver requirements.

One approach which should be considered is the development of "Parameter Identification" techniques for evaluating static and dynamic characteristics from wind tunnel tests. This test technique will not solve the low cross-flow Reynolds number problem for high angle-of-attack testing, but it can provide an alternative model mounting system and may result in more accurate rate derivative 
evaluation and more efficient wind tunnel testing.

\section{Materials}

The effort in this program area is directed almost exclusively to the development of lightweight and fire-resistant materials. The work described to the committee concerning the testing and analysis for internal aircraft materials appears to be of very high quality. The group, although small, is knowledgeable in the field, well established in the fundamental sense, with an objective of realistic application. This work represents an excellent combination of basic research and applications. It clearly can have a significant impact on future aircraft materials.

Both the Ames Research Center and the Johnson Space Center are working on fire resistant materials, but there is a lack of overall program direction within NASA. A focal point is needed -- one that would be responsible for coordinating the efforts of all NASA centers and interfacing with industry on this subject.

\section{Propulsion Environment}

Activity at Ames in this matter has been reduced to a low level of activity in propulsion noise research. Considering the activity in noise and emissions research taking place in industry and at Langley and Lewis, the level at Ames appears to be appropriate, allowing Ames to concentrate its resources in areas that exploit its unique capabilities. It is recommended that the use of the $40-$ by 80 -foot wind tunnel for research on forward velocity effects be integrated into programs managed by Langley and Lewis. 
End of Document 